\section{Missing gas saps plant theory}

A team of plant scientists has cast doubt on one of the most startling research results the field has seen in recent years - the finding that green plants emit methane. Tom Dueck of Plant Research International in Wageningen, the Netherlands, and his colleagues say that they can find no evidence that plants produce the potent greenhouse gas.

Depending on how the comparison is made, methane's greenhouse effect is between 25 and 70 times as great as that of carbon dioxide. Until last year, methane was thought to be produced almost exclusively by microbes either in natural settings, such as swamps, or artificial ones, such as landfills, and in the guts of domesticated cattle. The claim by Frank Keppler of the Max Planck Institute for Nuclear Physics in Heidelberg, Germany and his colleagues that plants also emit methane, published in Nature last year (439, 187-191; 2006), threatened to overturn this microbesonly view of the global methane cycle. According to Keppler's team, plants might account for up to $40 \%$ of the 580 million tonnes of the gas that are emitted every year.

The claim was immediately controversial, not least because Keppler's team could not come up with a metabolic mechanism for their lab-based observations. One reason that the matter has not already been settled is that the amount of methane produced by each plant is low relative to the ambient methane concentration. To tackle this problem, Dueck and his

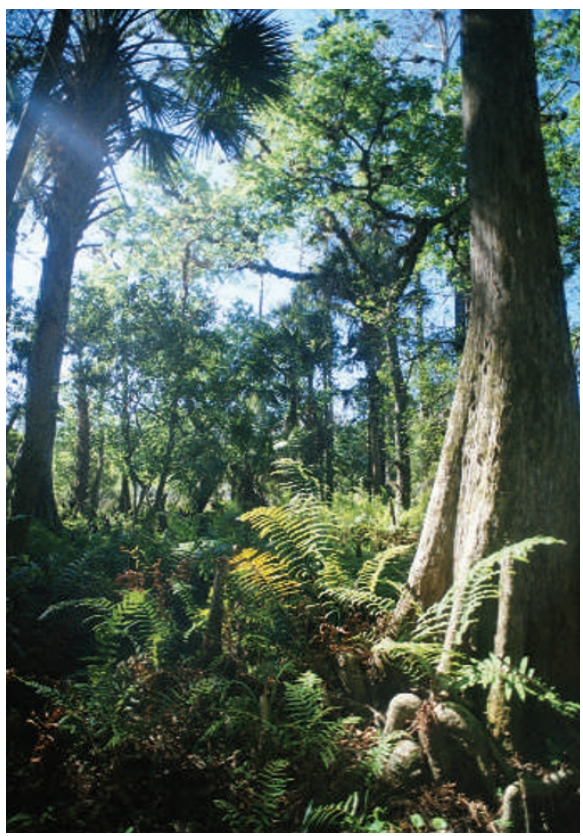

Plants might generate methane, but how? team grew plants in an atmosphere of 'heavy' carbon dioxide enriched in the isotope carbon13 to give any methane produced a recognizable isotopic signature. But their studies detected no significant methane emissions (New Phytol. doi:10.1111/j.1469-8137.2007.02103.x; 2007).

Dueck acknowledges the difficulty of attempting to prove a negative. "The discussion is definitely not ended here," he says. "We are very curious to see how this is going to go. But if you are going to look for a mechanism [for methane emission], first you have to be able to measure it."

Both groups have criticized the other's choice of experimental method. Dueck says that Keppler's group kept plants in sealed plastic containers instead of flow chambers, and exposed them to sources of stress such as bright sunlight and high temperature, which could have produced methane as an artefact. Keppler retorts that the use of ${ }^{13} \mathrm{C}$ is an artificial piece of chemical trickery with unknown effects on plant metabolism, and also argues that methane production can vary by up to three orders of magnitude between species.

Nevertheless, without a mechanism, Keppler's claim remains open to attack. "We are aware that while some scientific groups are having difficulties in repeating our work, several others have been able to do so and their results agree with our findings," Keppler says. These confirmatory results have yet to be published.

Meanwhile, another plant scientist, David Beerling of the University of Sheffield, UK, says that he has not seen any methane using a method that is similar to Dueck's, but without relying on ${ }^{13} \mathrm{C}$. His research has not yet been published, but Beerling thinks that if it joins Dueck's in the peer-reviewed literature, "the two together could kill off the theory".

The problem of how to explain puzzlingly high methane levels found above certain forests remains. But in light of the new results, atmospheric scientist Ed Dlugokencky of the Earth System Research Laboratory in Boulder, Colorado, thinks that the most likely explanation is "another, perhaps anaerobic source that we haven't identified yet".

But even if the theory can be verified, it is likely to have little bearing on regulations of man-made greenhouse-gas emissions, which are known to be just over half of the global total, Dlugokencky says. "Total emissions are known pretty well from the top down," he says. "If methane emissions are coming from forests then that probably just means less from wetlands."

Michael Hopkin

\section{GOOD REASONS}

\section{For NASA to feel smug}

1 It has just helped Stephen Hawking (pictured) get his first taste of weightlessness, flying aboard a 'vomit comet' in preparation for a planned space journey next year.

\section{The STEREO} mission has captured the first threedimensional images of the Sun, which should make for better forecasts of the weather in space.

\section{Officials are expecting a visit from Britain's Queen Elizabeth II, who will drop in at the Goddard Space Center next week as part of a US tour. A flight on the vomit comet is not thought to be on Her Majesty's official itinerary.}

\section{SCORECARD}

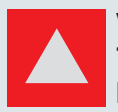

Victor Yushchenko The Ukrainian president has pledged to rehabilitate those affected by the Chernobyl accident and to develop the territory contaminated by the blast 21 years ago...although he might have to wait for the radiation to dissipate first.

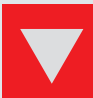

Anti-GM protestors Red faces for British activists, whose

meticulous plan to plant organic potatoes in a transgenic trial plot fell at the final hurdle - when they sabotaged the wrong field.

\section{ON THE RECORD (CIt's like a Thomas Hardy tragedy.")}

Massachusetts Institute of Technology's Leslie Perelman reacts to the resignation of the institute's dean of admissions Marilee Jones, who admits that she lied about her qualifications during her 28-year tenure.

Sources: NASA, Environment News Service, The Guardian, The New York Times

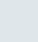

